\title{
Tücken der Korruption: Vier Fallbeispiele aus der Praxis
}

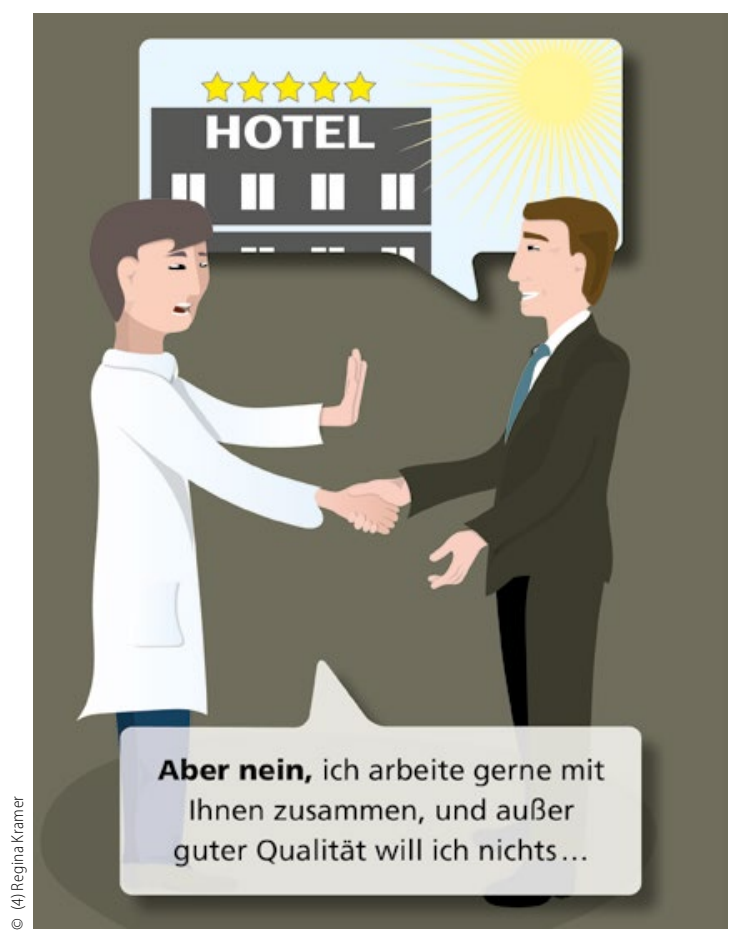

\section{Aufträge an ein Zahntechnik-Labor}

Zahnarzt Dr. Schliff arbeitet seit vielen Jahren mit einem Zahntechnik-Labor zusammen. Die Qualität stimmt und der Preis ebenfalls. So weit so gut: Jeder hat die freie Wahl seiner Kooperationspartner. Wo beginnt die Korruption? Wenn der Inhaber des Labors Kickbacks oder Prämien für die Aufträge aus der Zahnarztpraxis zahlt oder aber den Zahnarzt zu kleinen, feinen Wochenendreisen oder Ähnlichem einlädt, dann liegt der Verdacht der Korruption nahe. sas

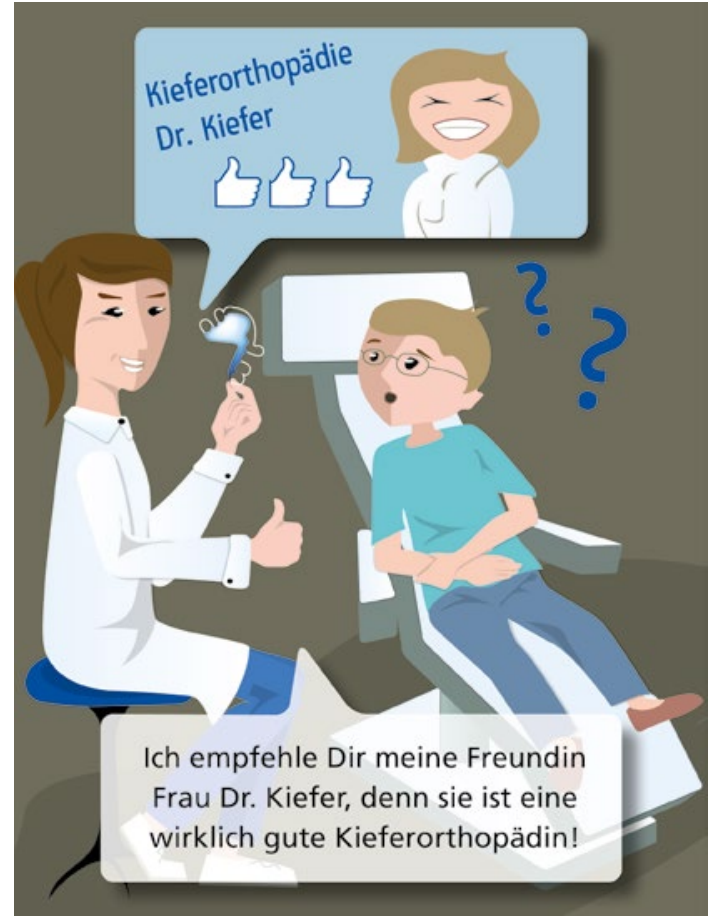

\section{Überweisung an Kieferorthopäden}

Zahnärztin Dr. Bohrer überweist regelmäßig Patienten an einen Kieferorthopäden, der nur zwei Straßen weiter seine Praxis hat. Von seinen Leistungen als Kieferorthopäde ist Dr. Bohrer überzeugt. Nichts dagegen zu sagen: Empfehlungen zu anderen (Fach-)Kollegen darf ein Arzt oder Zahnarzt aussprechen. Problematisch wird es nur, wenn diese Empfehlung abhängig ist von Zuwendungen - welcher Art auch immer.

\section{„Vorteile von externen Laboren sind hochkritisch“}

\begin{abstract}
Das Antikorruptionsgesetz im Gesundheitswesen geht in eine neue Runde. Der Kabinettsentwurf hat nach seiner Veröffentlichung hohe Wogen geschlagen, im November geht nun die überarbeitete Version in die erste Lesung im Bundestag. Der DFZ hat bei Rechtsanwalt Dr. Oliver Pragal nachgefragt, was sich getan hat.
\end{abstract}

DFZ: Herr Dr. Pragal, Sie haben das Gesetzgebungsverfahren für den Freien Verband Deutscher Zahnärzte intensiv beobachtet. Was ist Ihr Eindruck vom aktuellen Stand der Gesetzgebung?

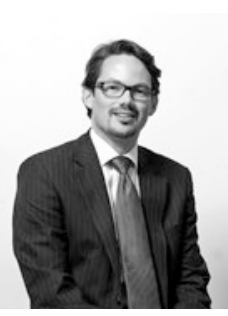

Pragal: Der vom Bundeskabinett am 29. Juli 2015 beschlossene Regierungsentwurf hat an dem Referentenentwurf des Bundesjustizministeriums einige durchaus gravierende Änderungen vorgenommen. Die wichtigste Änderung besteht in einer sehr ausführlichen Ergänzung der Entwurfsbegründung hinsichtlich der nötigen Rücksichtnahme auf Kooperationen im Gesundheitswesen. Im Großen und Ganzen werden redliche Ärzte mit diesem Tatbestand gut leben können und müssen keine ungerechtfertigte Kriminalisierung befürchten. Ich bin sicher, dass die Öffentlichkeit - und damit auch die Patienten - es erwarten, dass sich Ärz- teverbände jedenfalls grundsätzlich für eine solche Regelung gegen die wenigen „schwarzen Schafe“ aussprechen.

\section{DFZ: Was bedeutet dies für die Praxis?}

Pragal: Der Gesetzgeber hat auf mehr als einer Seite klargestellt dass die angemessene Vergütung von ärztlichen Tätigkeiten im Rahmen von zulässigen Kooperationen jedenfalls ohne weitere Umstände nicht als „Zuweisung gegen Entgelt“ bewertet werden darf. Gleiches gilt für gegenseitige Empfehlungen und Anwendungsbeobachtungen. Für die Zahnärzte ist besonders hervorzuheben, dass der Betrieb von Eigenlaboren ausdrücklich von jeder Korruptionsstrafbarkeit ausgenommen worden ist. Damit ist der Gesetzgeber in einem sehr wichtigen Punkt den Kritikern des Referentenentwurfs entgegengekommen.

DFZ: Geht Ihnen diese Entschärfung des Gesetzes weit genug? Pragal: Nicht ganz. Denn es verbleiben mit dieser Einschränkung Unsicherheiten für neuartige Kooperationsformen, die noch nicht eindeutig sozialrechtlich etabliert sind, jedoch aus Sicht der Ärzte - gegebenenfalls unter anwaltlicher Beratung vertretbar erscheinen (zum Beispiel Qualitätsnetzwerke, Übertragung von Tätigkeiten an der Schnittstelle zwischen ambulantem und stationärem Bereich). Es ist aber angesichts der he- 